\title{
Accurate identification of the six human Plasmodium spp. causing imported malaria, including Plasmodium ovale wallikeri and Plasmodium knowlesi
}

\author{
Adriana Calderaro*, Giovanna Piccolo, Chiara Gorrini, Sabina Rossi, Sara Montecchini, Maria Loretana Dell'Anna, \\ Flora De Conto, Maria Cristina Medici, Carlo Chezzi and Maria Cristina Arcangeletti
}

\begin{abstract}
Background: Accurate identification of Plasmodium infections in non-endemic countries is of critical importance with regard to the administration of a targeted therapy having a positive impact on patient health and management and allowing the prevention of the risk of re-introduction of endemic malaria in such countries. Malaria is no longer endemic in Italy where it is the most commonly imported disease, with one of the highest rates of imported malaria among European non-endemic countries including France, the UK and Germany, and with a prevalence of 24.3\% at the University Hospital of Parma. Molecular methods showed high sensitivity and specificity and changed the epidemiology of imported malaria in several non-endemic countries, highlighted a higher prevalence of Plasmodium ovale, Plasmodium vivax and Plasmodium malariae underestimated by microscopy and, not least, brought to light both the existence of two species of P. ovale (Plasmodium ovale curtisi and Plasmodium ovale wallikeri) and the infection in humans by Plasmodium knowlesi, otherwise not detectable by microscopy.
\end{abstract}

Methods: In this retrospective study an evaluation of two real-time PCR assays able to identify P. ovale wallikeri, distinguishing it from $P$. ovale curtisi, and to detect $P$. knowlesi, respectively, was performed applying them on a subset of 398 blood samples belonging to patients with the clinical suspicion of malaria.

Results: These assays revealed an excellent analytical sensitivity and no cross-reactivity versus other Plasmodium spp. infecting humans, suggesting their usefulness for an accurate and complete diagnosis of imported malaria. Among the 128 patients with malaria, eight $P$. ovale curtisi and four $P$. ovale wallikeri infections were detected, while no cases of $P$. knowlesi infection were observed.

Discussion and conclusions: Real-time PCR assays specific for P. ovale wallikeri and P. knowlesi were included in the panel currently used in the University Hospital of Parma for the diagnosis of imported malaria, accomplishing the goal of adhering to the recommendations of the World Health Organization to countries that are malaria-free to include the improvement of the early diagnosis of all cases of imported malaria.

Keywords: Imported malaria, Real-time PCR, Diagnosis

\footnotetext{
* Correspondence: adriana.calderaro@unipr.it

Unit of Microbiology and Virology, Department of Clinical and Experimental

Medicine, Faculty of Medicine and Surgery, University of Parma, Viale A.

Gramsci 14, Parma, Italy
}

\section{Biomed Central}

(c) 2013 Calderaro et al.; licensee BioMed Central Ltd. This is an Open Access article distributed under the terms of the Creative Commons Attribution License (http://creativecommons.org/licenses/by/2.0), which permits unrestricted use, distribution, and reproduction in any medium, provided the original work is properly cited. 


\section{Background}

Malaria, while the major cause of morbidity and mortality in adults and children worldwide [1] in endemic regions, is no longer endemic in Italy where it is the most commonly imported disease [2-4], with one of the highest rates of imported malaria among European non-endemic countries including France, the UK and Germany [5]. In the last decade, the routine use of molecular methods has transformed the epidemiology of malaria: in particular they enabled the identification of significantly more infections caused by Plasmodium species other than Plasmodium falciparum and of more mixed infections than detected by microscopy; molecular methods also highlighted both the existence of two distinct nonrecombining species of Plasmodium ovale (classic type Plasmodium ovale curtisi and variant type Plasmodium ovale wallikeri) [6], and the infection in humans by Plasmodium knowlesi $[7,8]$.

Different studies on $P$. ovale reported that $P$. ovale wallikeri is not confined to Southeast Asia but it circulates in African communities and that the two P. ovale species are generally sympatric in the countries where they occur $[2,6]$.

On the other hand, P. knowlesi, that naturally occurs in macaques inhabiting forested areas of Southeast Asia [8], has developed the ability to naturally infect humans so that it is now recognized as the fifth species of Plasmodium causing malaria in humans $[9,10]$ where it causes a spectrum of disease and where it can be fatal if not treated promptly $[9,11,12]$. Plasmodium knowlesi is widespread in humans in Malaysian Borneo [13-16] and the detection of $P$. knowlesi infections in travellers from Southeast Asia has been increasing [17] due to the availability of specific molecular assays able to reveal them. In particular, in Europe a few cases were described in Sweden [18], in The Netherlands [19], in Spain [20], and in Finland [21], but until now no data are available about imported P. knowlesi malaria cases in Italy. Therefore, Plasmodium knowlesi malaria should be considered in the differential diagnosis of any febrile traveller returning from forested areas of Southeast Asia [22]. The morphological resemblance of early trophozoites of $P$. knowlesi to P. falciparum and later erythrocytic stages of Plasmodium malariae makes it extremely difficult to identify P. knowlesi infections by microscopy only [15], emphasizing the need for the application of specific molecular assays [2,3,7].

In the light of these emerging epidemiological features, the molecular methods for the diagnosis of malaria caused by P. falciparum, Plasmodium vivax, P. ovale, and $P$. malariae in the laboratory located in the tertiarycare University Hospital of Parma $[2,23,24]$ were recently implemented with real-time PCR assays able to identify $P$. ovale wallikeri, to distinguish it from P. ovale curtisi, and to detect $P$. knowlesi, respectively [2,7].
In this retrospective study an evaluation of these two latter molecular assays and the application of them on a subset of 398 blood samples were performed. Samples were chosen on the basis of broadly reflecting the epidemiological picture of imported malaria at the University Hospital of Parma (a higher prevalence of infections by $P$. falciparum, followed by $P$. ovale, $P$. vivax and $P$. malariae) and including all the samples available in the laboratory belonging to patients coming from Southeast Asia and that could therefore have an infection by P. knowlesi. This was done also in order to reveal the potential presence of mixed infections, including $P$. ovale wallikeri or P. knowlesi, otherwise undiagnosed, among the blood samples tested in the study and belonging to patients with clinical suspicion of malaria.

\section{Methods}

\section{Samples}

A subset of 398 blood samples collected between 2000 and 2012 at the University Hospital of Parma from 398 patients presenting on admission with signs and symptoms consistent with malaria was used. Countries of origin/visit of the 398 patients were: Africa (269 patients), Southeast Asia (25 patients), and South America (14 patients). For 81 patients the origin was unknown. The remaining nine patients referred no recent travel to endemic areas. The samples analyzed in this and previous studies had been obtained by the University Hospital of Parma for routine diagnosis purposes, as such no approval by the local review committee was required because of the laboratory diagnosis results had been reported in the medical records of the patients as a diagnostic answer to a clinical suspicion of malaria.

\section{Diagnostic methods}

Microscopy was performed according to standard procedures as previously described [2,3,24]. Genomic DNA was purified as previously described [2] and subjected to routinely used molecular methods; an aliquot was stored at $-20^{\circ} \mathrm{C}$ for further examination. According to the results of microscopic examination (negative or positive), the purified DNA were subjected to a genus-specific nested- or real-time PCR assay $[25,26]$ or to speciesspecific nested- or real-time PCR assays for P. falciparum, $P$. vivax, $P$. ovale curtisi, and $P$. malariae, respectively, all targeting the $18 \mathrm{~S}$ ribosomal RNA gene of Plasmodium $[2,3,23]$.

The DNA purified from all 398 samples was subjected to real-time PCR assay for P. knowlesi [7] and that from 383 samples was subjected to real-time PCR assay for P. ovale wallikeri (for 15 among the 398 samples, the results of $P$. ovale curtisi and $P$. ovale wallikeri real-time PCR assays were previously reported [2]). 
Each experiment included a negative control (a reaction mixture without DNA), and a positive control consisting of a synthetic $P$. ovale wallikeri target sequence. For specific real-time PCR, a synthetic DNA oligonucleotide containing a target sequence of $P$. knowlesi ssrRNA gene (synthesized by TIB Molbiol S.r.l., Genova, Italy) was used. Each blood sample negative for Plasmodium spp. was submitted to a Taq-Man based real-time PCR assay specific for the human $\beta$-actin gene as previously described [27], in order to assess both the success in DNA extraction and the absence of inhibitors of the DNA polymerase.

The analytical sensitivity and specificity of the realtime PCR assay specific for $P$. ovale wallikeri were previously assessed on a small number of samples [2]. In the present study, the specificity of this real-time PCR assay versus species of the genus Plasmodium other than $P$. ovale wallikeri was tested by analysing the samples positive for the other human plasmodial species included in the 398 samples assayed.

The detection limit of the P. knowlesi real-time PCR assay was determined by analysing in duplicate ten-fold dilutions in sterile double-distilled water of the synthetic $P$. knowlesi rDNA oligonucleotide, ranging from $50 \times 10^{12}$ copies $/ \mu$ l to a theoretical value of 0.01 copies $/ \mu$ l. The analytical specificity of the new $P$. knowlesi real-time PCR was tested using genomic DNA samples from in vitro cultures of blood protozoa other than Plasmodium spp., such as Toxoplasma gondii and Leishmania infantum. The specificity of the P. knowlesi real-time PCR assay versus species of the genus Plasmodium, other than P. knowlesi, was tested by analysing the samples positive for the other human plasmodial species included in the 398 tested in this study. Each real-time PCR run was performed testing all the samples, including controls, in duplicate.

\section{Results}

Microscopy was positive for the presence of malaria parasites in 126 cases $(31.7 \%)$ of the 398 samples analysed (Table 1): 101 P. falciparum (80.2\%), nine P. vivax (7.1\%), seven $P$. ovale (5.5\%), one mixed infection P. falciparum + P. ovale $(0.8 \%)$, and eight Plasmodium spp. (6.4\%). The parasitaemia values ranged from $<0.001$ to $31.27 \%$ in the smears positive for $P$. falciparum, from 0.05 to $0.47 \%$ in the case of $P$. vivax, and from $<0.01$ to $1.18 \%$ in the case of $P$. ovale infections. In the Plasmodium spp. infections parasitaemia ranged from $<0.001$ to $0.6 \%$. In the case of the mixed infection revealed by microscopy the parasitaemia was $4 \%$. The highest parasitaemia value $(31.27 \%)$ was observed in the blood smear belonging to a 43-year old African patient infected with $P$. falciparum presenting with fever, jaundice and thrombocytopaenia. The remaining 272 samples $(68.3 \%)$ were negative by microscopy (Table 1$)$.
Table 1 Different species of Plasmodia as detected by microscopy and by real-time PCR assays

\begin{tabular}{|c|c|}
\hline \multirow[t]{2}{*}{ Microscopy } & Real-time PCR assays \\
\hline & $\mathrm{Pf} / \mathrm{Po} / \mathrm{Poc} / \mathrm{Pm} / \mathrm{Pv} / \mathrm{Pow} / \mathrm{Pk}$ \\
\hline \multirow[t]{3}{*}{$101 P f$} & $99 P f$ \\
\hline & $1 P_{0}$ \\
\hline & 1 mixed $P f+P o c+P m$ \\
\hline \multirow[t]{3}{*}{$9 P_{V}$} & $7 P V$ \\
\hline & $1 P O C$ \\
\hline & $1 P m$ \\
\hline \multirow[t]{3}{*}{7 Po } & 5 POC \\
\hline & 1 Pow \\
\hline & $1 P_{0}$ \\
\hline 1 mixed $P f+P_{0}$ & $1 P f$ \\
\hline \multirow[t]{6}{*}{8 Plasmodium spp. } & $2 P f$ \\
\hline & 2 Pow \\
\hline & 1 POC \\
\hline & 1 mixed $P f+P m$ \\
\hline & 1 mixed $P f+P o w$ \\
\hline & 1 mixed $P f+P_{0}$ \\
\hline \multirow[t]{2}{*}{2 negative } & $1 P f$ \\
\hline & $1 P m$ \\
\hline 270 negative & 270 negative \\
\hline
\end{tabular}

The real-time PCR assays revealed Plasmodiumspecific DNA in 128 cases (32.1\%) of the 398 samples analysed (Table 1): 103 P. falciparum (80.5\%), seven $P$. vivax (5.5\%), seven $P$. ovale curtisi (5.5\%), three $P$. ovale wallikeri (2.4\%), two $P$. ovale (1.6\%), two $P$. malariae (1.6\%), one mixed infection $P$. falciparum $+P$. ovale wallikeri $(0.8 \%)$, one P. falciparum $+P$. ovale curtisi + $P$. malariae $(0.8 \%)$, one $P$. falciparum + P.ovale $(0.8 \%)$, and one P. falciparum $+P$. malariae $(0.8 \%)$. In the cases reported as $P$. ovale (three single infections and one mixed), $P$. ovale curtisi and P. ovale wallikeri specific real-time PCRs assays were not performed due to the unavailability of residual original samples. The cycle threshold $(\mathrm{Ct})$ values for the samples positive for $P$. ovale wallikeri ranged from 30.30 to 45.19 for the three single infections and 34.01 for the mixed infection. The remaining 270 samples (67.9\%) were negative by realtime PCR assays (Table 1).

The P. knowlesi-specific real-time PCR assay gave a negative result for all 398 samples tested. The demographic data of all the 128 malaria cases regarding sex, fever, anti-malarial chemoprophylaxis, and country of origin/visit are shown in Figure 1. No cross-reactivity was detected with the $P$. ovale wallikeri real-time PCR 

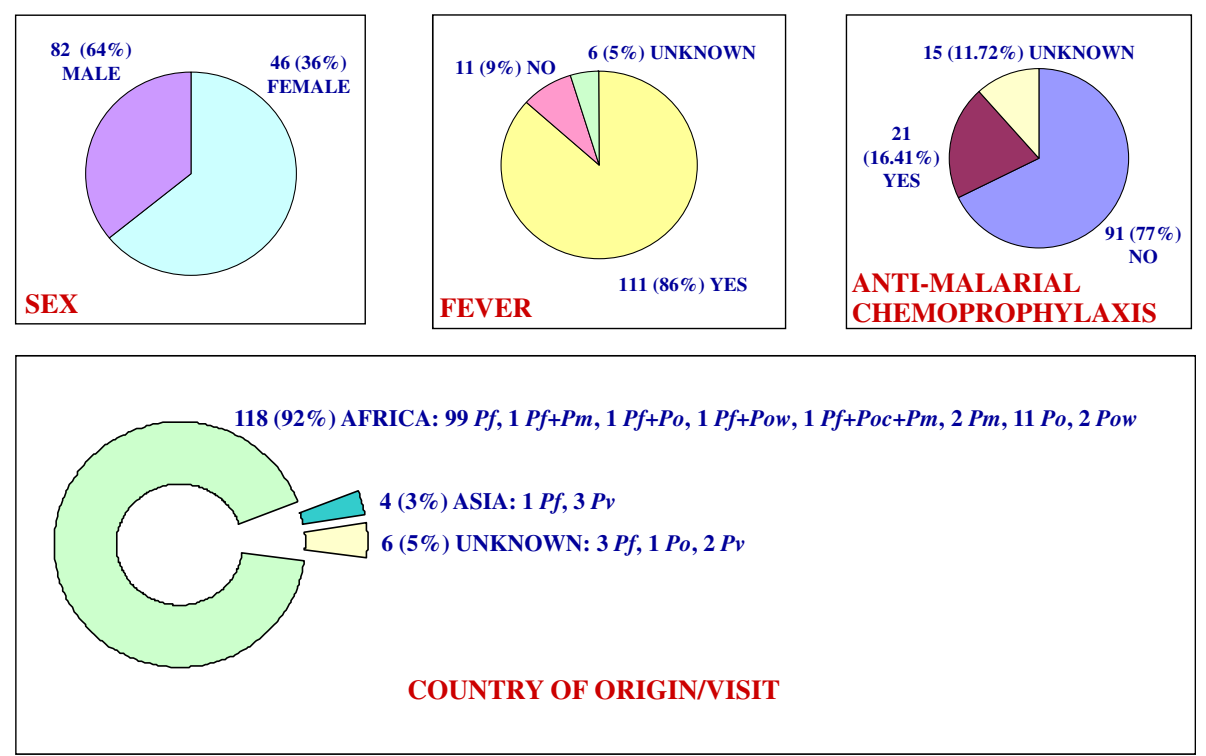

Figure 1 Demographic data of the 128 patients with malaria diagnosed by $P C R$ assays. $P f=P$. falciparum; $P \vee=P$. vivax; $P \circ C=P$. ovale $c u r t i s i$; $P o w=P$. ovale wallikeri; $P m=P$. malariae; $P k=P$. knowlesi.

assay when the 121 samples positive for different plasmodial species (P. falciparum, P. malariae, P. ovale curtisi, and $P$. vivax) were analysed, neither was a signal detected for any of the negative controls.

The detection limit of P. knowlesi real-time PCR assay was equal to a value of about ten copies/reaction. No cross-reactivity was detected with the P. knowlesi realtime PCR assay when the DNA purified from $T$. gondii, $L$. infantum and from the 128 samples positive for different plasmodial species (P. falciparum, P. malariae, $P$. ovale curtisi, $P$. ovale wallikeri, and $P$. vivax) were analysed, neither was a signal detected for any of the negative controls. All the negative samples for Plasmodium spp. were positive for the presence of the human $\beta$-actin gene.

\section{Discussion}

Malaria is the most commonly imported disease in Italy as well as observed in Parma where its prevalence is about $24.3 \%$ (272 positive patients on a total of 1,117 patients presenting to University Hospital of Parma with the suspicion of malaria) [3]. The existence of two different species of $P$. ovale ( $P$. ovale curtisi and $P$. ovale wallikeri) and the appearance in Europe of imported malaria cases by P. knowlesi make necessary the use of diagnostic assays able to detect them. Therefore, a panel of real-time PCR assays for the detection of P. falciparum, $P$. vivax, $P$. ovale curtisi, and $P$. malariae used at the University Hospital of Parma was implemented with a real-time PCR assay specific for $P$. ovale wallikeri, newly described by Calderaro et al. [2], and a real-time PCR assay for the detection of $P$. knowlesi, previously described in the literature [7]. The panel of real-time PCR assays currently used at the University Hospital of Parma for the diagnosis of malaria constitutes a robust system because it has been thoroughly validated in previous studies compared to reference molecular methods, including reference nested-PCR and genetic sequence analysis [23-25].

Regarding the P. ovale wallikeri real-time PCR assay, a brief evaluation including the detection limit and the analytical specificity previously made on a smaller number of samples was expanded by testing a greater amount of samples $[2,5,8,23]$.

In this study, both the $P$. ovale wallikeri and $P$. knowlesi real-time PCR assays evaluated were proven to be very specific since no cross-reactivity was observed with the DNA obtained from the positive 128 samples containing other Plasmodium species, with the DNA obtained from blood protozoa other than Plasmodium, and with the DNA from the 270 negative samples for malaria (the veracity of which was guaranteed by the positivity of the $\beta$-actin internal control system and the negative results by the genus-specific PCR assays).

This finding is of particular importance regarding $P$. knowlesi given the inability of microscopy to diagnose infections by this species $[15,17]$ which leads to the need for a thorough investigation to assess the correct prevalence of this parasite in the human population. On the contrary, some P. knowlesi-specific molecular methods previously described were reported to show cross-reactivity with other human Plasmodium spp. [28,29]. The 4/128 patients with malaria who came from Southeast Asia and the 6/128 of unknown origin, representing in this study the group of patients with the possibility of being infected 
with $P$. knowlesi, were all negative, highlighting in the population of patients tested the absence until now of cases of imported malaria by this species. The same result was obtained on 97 samples from patients without malaria coming from Southeast Asia or of unknown origin (that may, therefore, have come from Southeast Asia), already found to be negative by the genus-specific PCR assays. As expected, all the samples from African patients were negative for the presence of $P$. knowlesi. This assay showed in this study also an excellent analytical sensitivity, having a detection limit of about ten target copies/reaction, even if, while unfortunately, the clinical sensitivity of the assay could not be evaluated due to the lack of P. knowlesi-positive samples in the panel of samples analysed in the study.

This study, like many others already described in the literature $[2,3,24,25,30]$, emphasizes once again the usefulness of molecular methods in the diagnosis of malaria as compared to the traditional microscopic investigation. The molecular assays revealed two additional single infections (one $P$. falciparum and one $P$. malariae) missed by microscopy, probably due to the very low presence of Plasmodium spp. [2,3,25]: the first case was a 26-year old Nigerian woman in Italy for one day with fever and abdominal pain for several days and the second was a 34-year old Ghanaian woman in Italy for five months with no clinical suspicion of malaria, but with fever after surgery for the removal of an abdominal and pelvic mass and subjected to a check for tropical diseases. Moreover, the molecular assays gave species identification in $6.3 \%(8 / 128)$ of the positive samples, revealing five single and three mixed infections in which plasmodial species had not been identified, limiting the results to genus identification (Plasmodium spp.). In such cases, the misdiagnosis by microscopy of the mixed infections can be due to the dominance of one parasite over the co-infecting one [3,31]. Microscopy did not reveal one mixed infection diagnosed by PCRs while one reported as a mixed infection by microscopy was not subsequently confirmed by molecular assays. Microscopy gave an incorrect diagnosis in $1.5 \%(2 / 128)$ of the positive cases, mistaking $P$. vivax with $P$. ovale and $P$. malariae, likely due to the fact that these infections do not reach as high parasite levels as those by $P$. falciparum.

Figure 2 shows the flow-chart currently adopted at the University Hospital of Parma for the diagnosis of imported malaria in the light of the results obtained in the present study.

\section{Conclusions}

In this study the real-time PCR assays specific for P. ovale wallikeri and P. knowlesi were proven to be powerful diagnostic tools able to provide a novel insight into the epidemiology of malaria infections in a non-endemic area. Any meaningful investigations of the true epidemiology and biology of the two $P$. ovale variants, indistinguishable by microscopy, should include the application of sensitive and specific molecular methods of detection. Since the number of human infections by $P$. knowlesi is increasing, clinicians and laboratory personnel should be alert to this emerging species [32], and the potential cause of lethal malaria in humans, especially because it can be confused with the less dangerous species $P$. malariae by microscopic examination.

Real-time PCR assays specific for P. ovale wallikeri and $P$. knowlesi were included in the panel currently used in

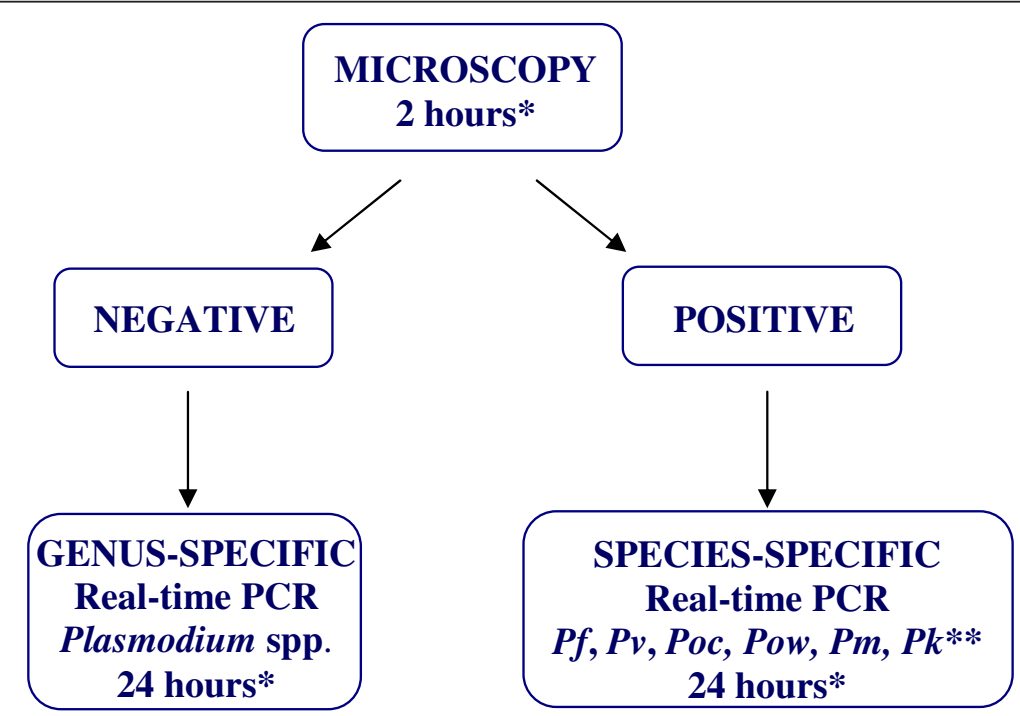

Figure 2 Malaria diagnosis flow-chart. $P f=P$. falciparum; $P v=P$. vivax; $P o C=P$. ovale curtisi; $P o w=P$. ovale wallikeri; $P m=P$. malariae; $P k=P$. $k n o w l e s i$. * time for producing the clinical report from the arrival of the sample; ** only in cases of patients from Southeast Asia. 
the University Hospital of Parma for the diagnosis of imported malaria, accomplishing the goal of adhering to the recommendations of the World Health Organization to countries that are malaria-free to include the improvement of the early diagnosis of all cases of imported malaria, among other specific programme objectives [33].

\section{Competing interests}

The authors declare that there are no competing interests.

\section{Authors' contributions}

$A C$ and GP conceived and designed the experiments. GP, CG, SM and SR performed the experiments. AC, GP, CG, SM, MLD, FDC, MCM, CC, and MCA analysed the data. AC contributed reagents/materials/analysis tools. AC, GP and CG wrote the paper. All authors read and approved the final manuscript.

\section{Acknowledgements}

This work was supported by a grant from the "Fondazione Cariparma" 2011-2013 (Italy) and by the Ministry of University and Scientific Research grant FIL (Parma, Italy).

Received: 11 July 2013 Accepted: 9 September 2013

Published: 13 September 2013

\section{References}

1. WHO: World Malaria Report 2011. Geneva: World Health Organization; 2011.

2. Calderaro A, Piccolo G, Gorrini C, Montecchini S, Rossi S, Medici MC, Chezzi C, Snounou G: A new real-time PCR for the detection of Plasmodium ovale wallikeri. PLoS One 2012, 7:e48033.

3. Calderaro A, Gorrini C, Peruzzi S, Piccolo G, Dettori G, Chezzi C: An 8-year survey on the occurrence of imported malaria in a non endemic area by microscopy and molecular assays. Diagn Microbiol Infect Dis 2008, 61:434-439.

4. Romi R, Sabatinelli G, Majori G: Could malaria reappear in Italy? Emerg Infect Dis 2001, 7:915-919.

5. Askling HH, Bruneel F, Burchard G, Castelli F, Chiodini PL, Grobush MP, Lopez-Velez R, Paul M, Petersen E, Popescu C, Ramharter M, Schlagenhauf P, on behalf of the European Society for Clinical Microbiology and Infectious Diseases Study Group on Clinical Parasitology: Management of imported malaria in Europe. Malar J 2012, 11:328.

6. Sutherland CJ, Tanomsing N, Nolder D, Oguike M, Jennison C, Pukrittayakamee S, Dolecek C, Hien TT, do Rosário VE, Arez AP, Pinto J, Michon P, Escalante AA, Nosten F, Burke M, Lee R, Blaze M, Otto TD, Barnwell JW, Pain A, Williams J, White NJ, Day NPJ, Snounou G, Lockhart PJ, Chiodini PL, Imwong M, Polley SD: Two nonrecombining sympatric forms of the human malaria parasite Plasmodium ovale occur globally. I Infect Dis 2010, 201:1544-1550.

7. Divis PC, Shokoples SE, Singh B, Yanow SK: A TaqMan real-time PCR assay for the detection and quantitation of Plasmodium knowlesi. Malar J 2010, 9:344.

8. Singh B, Sung LK, Matusop A, Radhakrishnan A, Shamsul SSG, Cox-Singh J, Thomas A: A large focus of naturally acquired Plasmodium knowlesi infections in human beings. Lancet 2004, 363:1017-1024.

9. Singh B, Daneshvar C: Human infections and detection of Plasmodium knowlesi. Clin Microbiol Rev 2013, 26:165.

10. Obare P, Ogutu B, Adams M, Odera JS, Lilley K, Dosoo D, Adhiambo C, Owusu-Agyei S, Binka F, Wanja E, Johnson J: Misclassification of Plasmodium infections by conventional microscopy and the impact of remedial training on the proficiency of laboratory technicians in species identification. Malar J 2013, 12:113.

11. William T, Menon J, Rajahram G, Chan L, Ma G, Donaldson S, Khoo S, Fredrick C, Jelip J, Anstey M, Yeo TW: Severe Plasmodium knowlesi malaria in a tertiary care hospital, Sabah, Malaysia. Emerg Infect Dis 2011, 17:1248-1254

12. Cox-Singh J, Hiu J, Lucas SB, Divis PC, Zulkarnaen M, Chandran P, Wong KT, Adem P, Zaki SR, Singh B, Krishna S: Severe malaria - a case of fatal Plasmodium knowlesi with post-mortem findings: a case report. Malar J 2010, 9:10.

13. Cox-Singh J, Singh B: Knowlesi malaria: newly emergent and of public health importance? Trends Parasitol 2008, 24:406-410.
14. Luchavez J, Espino F, Curameng P, Espina R, Bell D, Chiodini P, Nolder D, Sutherland C, Lee KS, Singh B: Human infections with Plasmodium knowlesi, the Philippines. Emerg Infect Dis 2008, 14:811-813.

15. Lee KS, Cox-Singh J, Brooke G, Matusop A, Singh B: Plasmodium knowlesi from archival blood films: further evidence that human infections are widely distributed and not newly emergent in Malaysian Borneo. Int Parasitol 2009, 39:1125-1128.

16. Goh XT, Lim YAL, Vythilingam I, Chew CH, Lee PC, Ngui R, Tan TC, Yap NJ, Nissapatom V, Chua KH: Increased detection of Plasmodium knowlesi in Sandakan division, Sabah as revealed by PlasmoNex. Malar J 2013, 12:264.

17. Oddoux O, Debourgogne A, Kantele A, Kocken CH, Jokiranta TS, Vedy S, Puyhardy JM, Machouart M: Identification of the five human Plasmodium species including $P$. knowlesi by real-time polymerase chain reaction. Eur J Clin Microbiol Infect Dis 2011, 30:597-601.

18. Bronner U, Divis PC, Färnert A, Singh B: Swedish traveller with Plasmodium knowlesi malaria after visiting Malaysian Borneo. Malar J 2009, 8:15.

19. van Hellemond JJ, Rutten M, Koelewijn R, Zeeman AM, Verweij JJ, Wismans PJ, Kocken $\mathrm{CH}$, van Genderen PJ: Human Plasmodium knowlesi infection detected by rapid diagnostic tests for malaria. Emerg Infect Dis 2009, 15:1478-1480.

20. Tang TTH, Salas A, Ali-Tammam M, Martinez MdC, Lanza M, Arroyo E, Rubio JM: First case of detection of Plasmodium knowlesi in Spain by Real-time PCR in a traveller from Southeast Asia. Malar J 2010, 9:219.

21. Kantele A, Jokiranta S: Plasmodium knowlesi-the fifth species causing human malaria. Duodecim 2010, 126:427-434.

22. Antinori S, Galimberti L, Milazzo L, Corbellino M: Plasmodium knowlesi: the emerging zoonotic malaria parasite. Acta Trop 2013, 125:191-201.

23. Perandin F, Manca N, Calderaro A, Piccolo G, Galati L, Ricci L, Medici MC, Arcangeletti MC, Snounou G, Dettori G, Chezzi C: Development of a real-time PCR assay for detection of Plasmodium falciparum, Plasmodium vivax, and Plasmodium ovale for routine clinical diagnosis. J Clin Microbiol 2004, 42:1214-1219

24. Calderaro A, Piccolo G, Perandin F, Gorrini C, Peruzzi S, Zuelli C, Ricci L, Manca N, Dettori G, Chezzi C, Snounou G: Genetic polymorphisms influence Plasmodium ovale PCR detection accuracy. J Clin Microbiol 2007, 45:1624-1627.

25. Snounou G, Singh B: Nested-PCR analysis of Plasmodium parasites. Methods Mol Biol 2002, 72:189-203.

26. Lee MA, Tan CH, Aw LT, Tang CS, Singh M, Lee SH, Chia HP, Yap EP: Real-time fluorescence-based PCR for detection of malaria parasites. J Clin Microbiol 2002, 40:4343-4345.

27. Calderaro A, Piccolo G, Gorrini C, Peruzzi S, Zerbini L, Bommezzadri S, Dettori G, Chezzi C: Comparison between two real-time PCR assays and a nested-PCR for the detection of Toxoplasma gondii. Acta Biomed 2006, 77:75-80.

28. Imwong M, Tanomsing N, Pukrittayakamee S, Day NP, White NJ, Snounou G: Spurious amplification of a Plasmodium vivax small-subunit RNA gene by use of primers currently used to detect $P$. knowlesi. J Clin Microbiol 2009, 47:4173-4175.

29. Sulistyaningsih E, Fitri LE, Loscher T, Berens-Riha N: Diagnostic difficulties with Plasmodium knowlesi infection in humans. Emerg Infect Dis 2010, 16:1033-1034.

30. Kaisar MM, Supali T, Wiria AE, Hamid F, Wammes LJ, Sartono E, Luty AJ, Brienen EA, Yazdanbakhsh M, van Lieshout L, Verweij JJ: Epidemiology of Plasmodium infections in Flores Island, Indonesia using real-time PCR. Malar J 2013, 12:169.

31. Sethabuter O, Brown A, Pantim S, Kain KC, Webster HK, Echeverria P: Detection of Plasmodium falciparum by polymerase chain reaction in a field study. J Infect Dis 1992, 166:145-146.

32. Sabbatani $S$, Fiorino $S$, Manfredi R: The emerging of the fifth malaria parasite (Plasmodium knowlesi). A public health concern? Braz I Infect Dis 2010, 14:299-309.

33. WHO: From malaria control to elimination in the WHO European Region 2006-2015. Copenhagen: World Health Organization Regional Office for Europe; 2006.

doi:10.1186/1475-2875-12-321

Cite this article as: Calderaro et al:: Accurate identification of the six human Plasmodium spp. causing imported malaria, including Plasmodium ovale wallikeri and Plasmodium knowlesi. Malaria Journal 2013 12:321. 